\title{
Effects of Lower Heat Value Fuel on the Operations of Micro-Gas Turbine
}

\author{
Aiguo LIU, Yiwu WENG \\ Key Laboratory of Machinery and Power Engineering of Education Ministry, Shanghai Jiao Tong University, Shanghai, China \\ Email: liuaiguo119@gmail.com
}

\begin{abstract}
The characteristics of fuel from biomass, coal and some waste materials are lower heat value and different compositions. The lower heat value fuel (LHVF) can be used on power engine such as boiler, gas engine and gas turbine. Some laboratory and pilot work have been done, but the work done on micro-gas turbine is still limited. The characteristics of LHVF can cause the operations change of micro-gas turbine designed for nature gas. Some possible adjustment and modification methods were mentioned for the use of LHVF on micro-gas turbine. One kind of representative LHVF was chosen and the operations of micro-gas turbine were analyzed. The temperature field and the non-uniformity scale of temperature distribution of combustor were calculated using FLUENT. The feasibility of different adjustment and modification methods were analyzed according to the efficiency, output power and the non-uniformity scale of temperature distribution.
\end{abstract}

Keywords: lower heat value fuel, micro-gas turbine, operations

\section{Introduction}

The distribution of LHVF from biomass, coal and waste materials is wide and the energy reserves are huge [1]. Effective use of the LHVF is becoming an attractive project, and much work is being done in this field. The characteristics of LHVF are lower heat value and different combustible compositions compared with nature gas. Heat values of the fuel gases depend on the process, but are typically one-tenth to one-half that of natural gas [2].

It will be different for the use of LHVF compared with traditional fuel according to its characteristics, so some different methods have ever been mentioned for the use of low heat value fuel such as catalytic combustion [3-5]. Efficient conversion of LHVF to electrical power can be accomplished by gas turbines, preferably in combined cycle mode, where thermal efficiencies can be greater than $65 \%$. Simple open cycle, high pressure ratio machines can achieve efficiencies greater than $40 \%$ and form the basis for Integrated Gasification Combined Cycles [6]. Usually the combustion chamber of gas turbine was designed for higher heat value fuel, and some problems will appear when using LHVF as fuel. Catalytic combustion chamber can take the place of traditional one for the LHVF, but some defects will appear such as higher pressure and loss, slow reaction rate and so on. So the traditional combustion chamber is still important for the use of LHVF.

Primary issue for the gas turbine combustor when using LHVF is its large volumetric flows. The operations of micro-gas turbine will be changed and even stop work. The gas turbine should be adjusted and even modified to make the micro-gas turbine work smoothly. In this paper the effects of LHVF on the micro-gas turbine are firstly discussed, and then some possible methods of adjustment and modification are mentioned. The effects of mentioned methods to the operations of micro-gas turbine were presented and discussed. The feasibility was also discussed. At last the temperature field of combustion chamber was presented. The maximum temperature, average temperature, and non-uniformity coefficient at the outlet of combustor were calculated for the judgment 
of the feasibility.

\section{Model Description}

\subsection{LHVF Model}

The combustible components and heat value of LHVF are different since they are from different way such as biomass gasification, blast furnace tar and the coal mine ventilation air [1][7]. The compositions of 3 representative kinds of LHVF were shown in Table 1. The main combustible components from biomass gasification and blast furnace tar are hydrogen and carbon monoxide and in the coal mine ventilation is methane. But the effects of LHVF on the operations of micro-gas turbine are the same, so we choose a representative low heat value fuel from biomass gasification as an example to analyze. The LHVF includes different combustible components and the fuel is deal as composite variables. The thermodynamic property of gas is calculated according to the calculation manner of mixed fuel with incombustible component [8].

\subsection{Micro-Gas Turbine Model}

All of the calculations are based on the modeling of the micro-gas turbine C30 from CAPSTONE using the software of Matlab/Simulink [9]. The gas turbine is a single-shaft micro-gas turbine equipped with centrifugal compressor, radial turbine, combustion chamber and recuperator. The design compressor pressure ratio is 3.2 and the turbine inlet temperature (TIT) is $1173 \mathrm{~K}$. The design mass flow of $0.31 \mathrm{~kg} \mathrm{~s}^{-1}$ is assumed to produce roughly $30 \mathrm{~kW}$ power with an efficiency of $26 \%$ at ISO conditions. This single shaft gas turbine is capable of running at different shaft speed which generates higher flexibility.

The modeling of micro-gas turbine is possible by utilizing real steady state engine performance data [10]. In gas turbine cycles, the changed relationship between mass flow and pressure will cause a change in the operation point and efficiency. The features of a compressor can be described as functions of pressure ratio $\pi_{C}$, reduced flow $G \sqrt{T} / P$, reduced speed $n / \sqrt{T}$ and efficiency $\eta_{C}$. Performance maps are introduced for determination of the pressure and efficiency as a function of mass flow and shaft speed for the description of compressor. Figure 1 shows the performance map of compressor. It is assumed that off-design thermodynamic and flow processes are characterized by a continuous progression along the steady-state performance curves.

The turbine model can be processed using a similar method.

In the combustion chamber, the fuels is burned away which increases the temperature of the gas. The following reactions are considered in calculating the exit gas temperature of the combustor:

$$
\mathrm{CO}+1 / 2 \mathrm{O}_{2}=\mathrm{CO}_{2}+Q_{\mathrm{CO}}
$$

Table 1. Components in different low heat value fuel

\begin{tabular}{cccc}
\hline Composition $/ \%$ & Biomass gas & Blast furnace tar & $\begin{array}{c}\text { Coal mine } \\
\text { ventilation air }\end{array}$ \\
\hline $\mathrm{CO}_{2}$ & 13.0 & 18 & 0 \\
$\mathrm{O}_{2}$ & 1.65 & 0 & 20.79 \\
$\mathrm{CO}$ & 21.4 & 26 & 0 \\
$\mathrm{H}_{2}$ & 12.2 & 4 & 0 \\
$\mathrm{CH}_{4}$ & 1.87 & 2 & 1 \\
$\mathrm{~N}_{2}$ & 49.88 & 60 & 78.21 \\
\hline
\end{tabular}

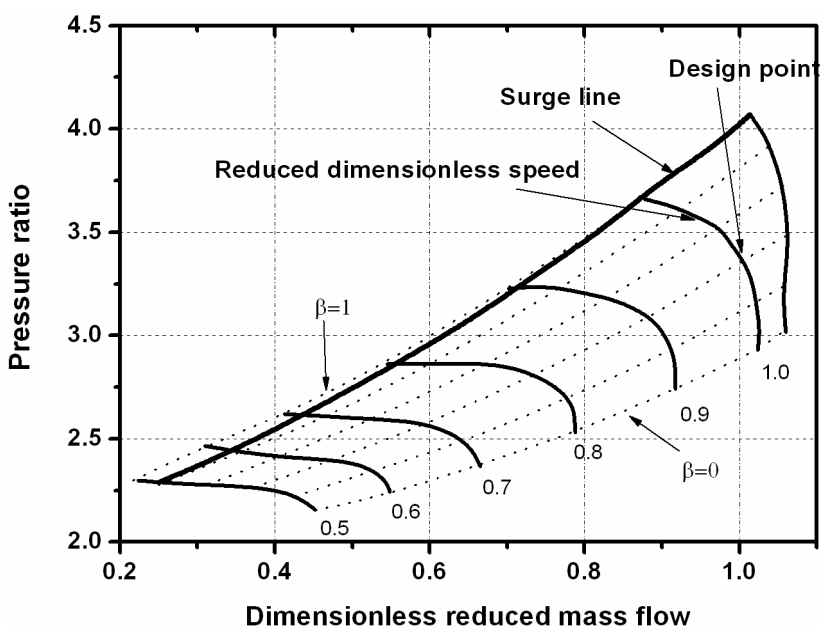

Figure 1. Equivalence circulates curve of compressor 


$$
\begin{gathered}
\mathrm{H}_{2}+1 / 2 \mathrm{O}_{2}=\mathrm{H}_{2} \mathrm{O}+Q_{\mathrm{H}_{2}} \\
\mathrm{CH}_{4}+2 \mathrm{O}_{2}=\mathrm{CO}_{2}+2 \mathrm{H}_{2} \mathrm{O}+Q_{\mathrm{CH}_{4}}
\end{gathered}
$$

Assuming that the process is adiabatic, the enthalpy of the reactants with combustion efficiency taken into account would be equal to the enthalpy of the products. Knowing the temperature of the reactants, the product temperature $T_{2}$ can be calculated by iteration as the properties of each product gas are temperature- dependent:

$$
\left(\Delta h+Q_{C O}+Q_{H_{2}}+Q_{C H_{4}}\right) \cdot \varepsilon_{c o m b}=\sum_{i} n_{i} \int_{T_{s t d}}^{T_{2}} c_{p m} d T
$$

where the $\Delta h$ is the enthalpy change of reactions from the original status to the standard status, the combustion efficiency $\varepsilon_{\text {comb }}$ was set conservatively at $98 \%$, though it can be as high as $99.5 \%$. $i$ represents each gas composition of the product.

The schematic figure of the recuperator is shown in Figure 2 Setting $p 2 、 h 2 、 p 4 、 h 4$ as the state variables, we can get the following equations based on the mass and energy balance [11][12].

$$
\begin{gathered}
\frac{d p_{2}}{d t}=\frac{\left(m_{2} h_{2}-m_{1} h_{1}-q_{h}\right)}{V_{h t}\left(1-c_{p 2} / R_{2}\right)} \\
\frac{d h_{2}}{d t}=\frac{\left(m_{1} h_{1}-m_{2} h_{2}+q_{h}\right)+\left(h_{2}-h_{2} R_{2} / c_{p 2}\right)\left(m_{2}-m_{1}\right)}{V_{h t}\left(\rho_{2}-R_{2} \rho_{2} / c_{p 2}\right)} \\
\frac{d p_{4}}{d t}=\frac{\left(m_{4} h_{4}-m_{3} h_{3}+q_{c}\right)}{V_{c l}\left(1-c_{p 4} / R_{4}\right)} \\
\frac{d h_{4}}{d t}=\frac{\left(m_{3} h_{3}-m_{4} h_{4}-q_{h}\right)+\left(h_{4}-h_{4} R_{4} / c_{p 4}\right)\left(m_{4}-m_{3}\right)}{V_{c l}\left(\rho_{4}-R_{4} \rho_{4} / c_{p 4}\right)}
\end{gathered}
$$

where $q_{h}, q_{c}$ are the heat transfer between fluid (hot and cold) and the wall of the recuperator.

$$
\begin{aligned}
& q_{h}=\alpha_{h} A_{h}\left(T_{12}-T_{m}\right) \\
& q_{c}=\alpha_{c} A_{c}\left(T_{m}-T_{34}\right)
\end{aligned}
$$

And the $T_{12}=\frac{T_{1}+T_{2}}{2}, T_{34}=\frac{T_{3}+T_{4}}{2}$ are the average value of inlet and outlet temperature respectively.
$T_{m}$ is the average wall temperature between the hot and cold side gas.

$$
\frac{d T_{m}}{d t}=\frac{1}{C_{p m} M_{m}}\left(q_{h}-q_{c}\right)
$$

The power output from the gas turbine is obtained by using the following equation:

$$
W_{G T}=\eta_{g e n}\left(\eta_{T} W_{t}-W_{c}\right)-W_{a u x}
$$

where $\eta_{g e n}$ is the generator efficiency; $\eta_{T}$ is the turbine mechanical efficiency; $W_{t}, W_{c}$ and $W_{a u x}$ are the turbine power, compressor power and auxiliary power respectively.

\subsection{CFD Model of Combustion Chamber}

The temperature field in the combustor will be changed; especially the temperature field of combustor outlet will have direct effect on the safety of turbine. The main analysis method of temperature field in combustor is CFD. Firstly the model was built by the software of $\mathrm{PRO} / \mathrm{E}$ and the plot of gridding is completed by Gambit using non-structure gridding, the number of gridding is 223271. The plot of gridding is shown in Figure 3. And

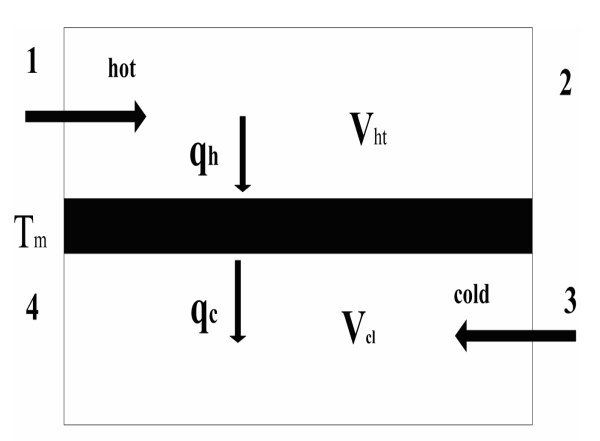

Figure 2. Schematic figure of heat transfer in the recuperator

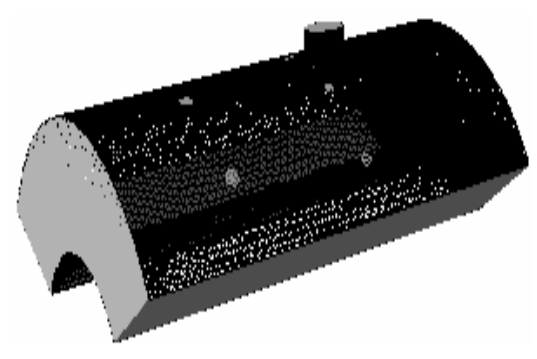

Figure 3. Gridding of annular combustor 
then the model was solved by the software of FLUENT.

\subsubsection{Flux Control Equation}

The flux control equation is N-S equation, the turbulence in combustor using $\kappa-\varepsilon$ double equation model. The $3 \mathrm{D}$ flux N-S equation in pole coordinate is as follows:

$\frac{1}{r}\left[\frac{\partial}{\partial x}(r \rho u \varphi)+\frac{\partial}{\partial r}(r \rho v \varphi)+\frac{\partial}{\partial \theta}(\rho w \varphi)\right]=$

$\frac{1}{r}\left[\frac{\partial}{\partial x}\left(\gamma \Gamma_{\varphi} \frac{\partial \varphi}{\partial x}\right)+\frac{\partial}{\partial r}\left(\Gamma_{\varphi} \frac{1}{r} \frac{\partial \varphi}{\partial r}\right)+\frac{\partial}{\partial \theta}\left(\Gamma_{\varphi} \frac{1}{r} \frac{\partial \varphi}{\partial \theta}\right)\right]+S_{\varphi}$

\subsubsection{Combustion Model}

The actual combustion process is the interaction of turbulence and chemistry reaction, the chemistry reaction velocity is strong nonlinear and strong stiff. Usual chemistry reaction mechanism includes tens of composition and hundreds of base reaction and the difference of reaction time is large. So the quantity of calculation and storage is very large in the solution of actual problem. The different chemistry dynamics solution methods have been used aims at the different combustion phenomena in FLUENT. The model used in this calculation is the Species Transport model. This model is usually used in the premixed combustion, part premixed combustion and diffusion combustion. The chemistry reaction is usually simplified as single-step reaction. The solution of the composition transport equation and getting the time-averaged mass fraction of each composition is as follows:

$$
\frac{\partial}{\partial t}\left(\rho Y_{i}\right)+\nabla\left(\rho \bar{v} Y_{i}\right)=-\nabla \bar{J}_{i}+R_{i}+S_{i}
$$

The reaction source item of composition $\mathrm{j}$ is the production rate of composition $\mathrm{j}$ in all the reactions:

$$
R_{i}=\sum_{k} R_{j k}
$$

In the formula, the reaction velocity of composition $\mathrm{j}$ in reaction $\mathrm{k}$ can be solved with the Arrhenius formula.

\section{Results and Discussion}

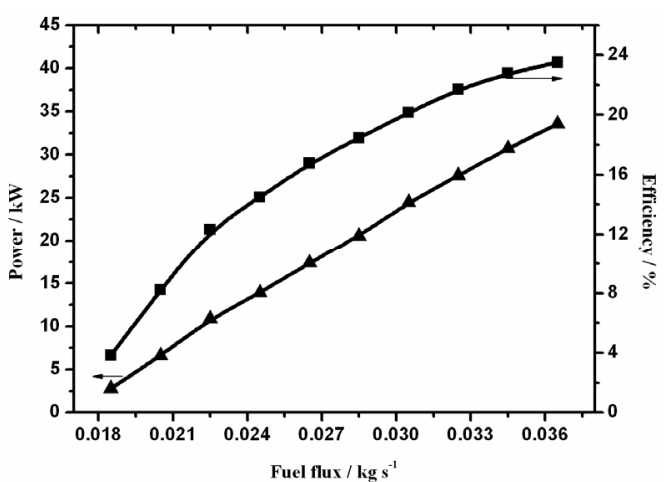

Figure 4. Relation of output power and efficiency to fuel flux

\subsection{Effects of LHVF on the Micro-Gas Turbine}

The energy provided by LHVF is less than the traditional fuel when the same fuel/air ratio was used. The fuel flux should be increased to improve the turbine inlet temperature. The relation of output power and efficiency with the fuel flux was shown in Figure 4 with the assumption of constant air flow.

The turbine inlet temperature (TIT) will increase with the increase of fuel flux which causes the increase of output power and efficiency. The TIT will not be the same with design value when the output power is the same with design value, so two special conditions have been presented according to the calculation. The first one was the output power of micro-gas turbine attained the design value (case2), the second one was the turbine inlet temperature attained the design value (case3). The calculation results were shown in Figure 5 and were compared with the design value (case1).

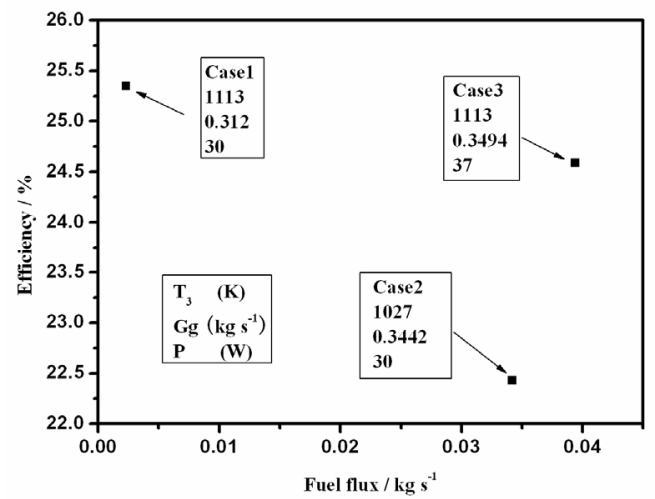

Figure 5. 3 different conditions 
From the calculation results in Figure 5 we can see the mass flow of fuel will be more than 14 times for case 2 and 16 times for case 3 compared with case1. The efficiency of case 2 and case 3 are both lower than caseland the output power is higher in case 3 . The decrease of efficiency is influenced by both the increase of the fuel flux entering combustor without being preheated and the decrease of turbine efficiency. About the increase of output power in case 3 is due to the increase of gas passing through turbine.

The mass flow of low heat value fuel will be more 10 times than the design value. There is flux difference between compressor and turbine, so the compressor and turbine can not match together. Some work should be done on the micro-gas turbine to make the compressor and turbine match again.

\subsection{Adjustment and Modification of Micro-Gas Turbine}

Some experience has been gained and adopted in heavy gas turbine for LHVF [13-16]. The heavy gas turbine can be adjusted in large scale to fit the operations of LHVF. For example, the flow ability of turbine can be increased $10 \%$, the compression ratio can be increased $12 \%$ and the output power can be increase $20 \%$ for the $9 \mathrm{~F}$ model heavy gas turbine from GE [17]. At the same time there exist variable-area nozzles which can be adjusted to decrease the flux of compressor. The adjustment methods used in heavy gas turbine do not all fit to the micro-gas turbine because the operations of micro-gas turbine are different from heavy gas turbine [18]. Some possible adjustment and modification methods were mentioned in this chapter and the feasibility was discussed.

\subsubsection{Adjustment of Micro-Gas Turbine}

\section{1) Pressure ratio and TIT}

The adjustment of operation parameters was viewed as the simplest method to match the compressor and turbine according to the experience of heavy gas turbine. The pressure ratio of compressor should be increased as high as possible because which can not only increase the flow ability of turbine but also decrease the flow ability of compressor. But the compression ratio can not be increased very high, so the turbine inlet temperature should be decreased at the same time for the purpose of matching. The adjustment process should be: firstly the compression ratio was increased as high as possible and then decreasing the TIT until the matching was achieved. The operation parameters were shown as case 4 in Table 2 for the adjustment of pressure ratio and TIT. From the results it was found that the efficiency and output power both decreased and the compressor has been near the surge boundary. So this adjustment method is inapplicable to the micro-gas turbine in the view of efficiency and output power.

Table 2. Four operation cases of micro-gas turbine in different condition

\begin{tabular}{|c|c|c|c|c|c|}
\hline \multirow{8}{*}{ Compressor } & & Case1 & Case4 & Case5 & Case6 \\
\hline & Rotation speed & $\mathrm{N}$ & $\mathrm{N}$ & $0.95 \mathrm{~N}$ & $0.9 \mathrm{~N}$ \\
\hline & Compression ratio & 3.2 & 3.257 & 3.09 & 2.634 \\
\hline & Outlet flux/ kg/s & 0.31 & 0.288 & 0.2782 & 0.2688 \\
\hline & Outlet temperature / K & 444 & 446.8 & 439.6 & 418 \\
\hline & Power $/ \mathrm{kW}$ & 47.1 & 44.42 & 40.8 & 33.33 \\
\hline & Outlet pressure/ $\mathrm{kPa}$ & 319.2976 & 324.98 & 308.3 & 262.8 \\
\hline & Efficiency & 0.818 & 0.82 & 0.8176 & 0.8107 \\
\hline \multirow{4}{*}{$\begin{array}{l}\text { Combustion } \\
\text { chamber }\end{array}$} & Fuel flux / kg /s & 0.002368 & 0.02527 & 0.03224 & 0.03188 \\
\hline & Inlet temperature / $\mathrm{K}$ & 839 & 662.7 & 807.9 & 886.2 \\
\hline & Outlet pressure / $\mathrm{kPa}$ & 309.7 & 316.7 & 300.6 & 255.6 \\
\hline & Outlet temperature / $\mathrm{K}$ & 1113 & 888.3 & 1072 & 1144 \\
\hline \multirow{4}{*}{ Turbine } & Outlet temperature / K & 912 & 718 & 877.5 & 964.1 \\
\hline & Outlet flux / kg/s & 0.312368 & 0.3164 & 0.3135 & 0.3037 \\
\hline & Power $/ \mathrm{kW}$ & 77.1 & 62.61 & 70.72 & 63.35 \\
\hline & Efficiency & 0.8164 & 0.8127 & 0.8072 & 0.8148 \\
\hline \multirow{2}{*}{$\begin{array}{l}\text { Micro-gas } \\
\text { turbine }\end{array}$} & Output power / kW & 30 & 17.69 & 30 & 30 \\
\hline & Efficiency / \% & 25.35 & 17.89 & 23.73 & 24.07 \\
\hline
\end{tabular}




\section{2) Rotation speed}

The matching between compressor and turbine can also be realized by adjusting the compressor itself to reduce the compressor air flux. There are several ways to adjust the compressor [19]:

(1) Outlet throttle;

(2) Inlet throttle;

(3) Variable rotation speed.

Whichever method will result in the increase of power consumed by compressor, and the variable rotation speed adjustment is the best way in the view of power consumption.

The variable rotation speed adjustment was chosen and the relationship of efficiency and output power with compression ratio was shown in Figure 6 and Figure 7 when the rotation speed is $0.95 \mathrm{~N}$ and $0.9 \mathrm{~N}(\mathrm{~N}$ is the design rotation speed value) respectively. The operation parameters are listed in Table 3 as case 5 and case 6 while keeping the output power as design value.

The power generated by turbine will decrease when the rotation speed decreases, but the power consumed by compressor also decreases at the same time. So the output of micro-gas turbine also can achieve the design value, but the efficiency will decrease due to the decrease of turbine and compressor efficiency. When the rotation speed is $0.9 \mathrm{~N}$ the turbine inlet temperature was higher than the design value for the design output power which can result exceeding temperature.

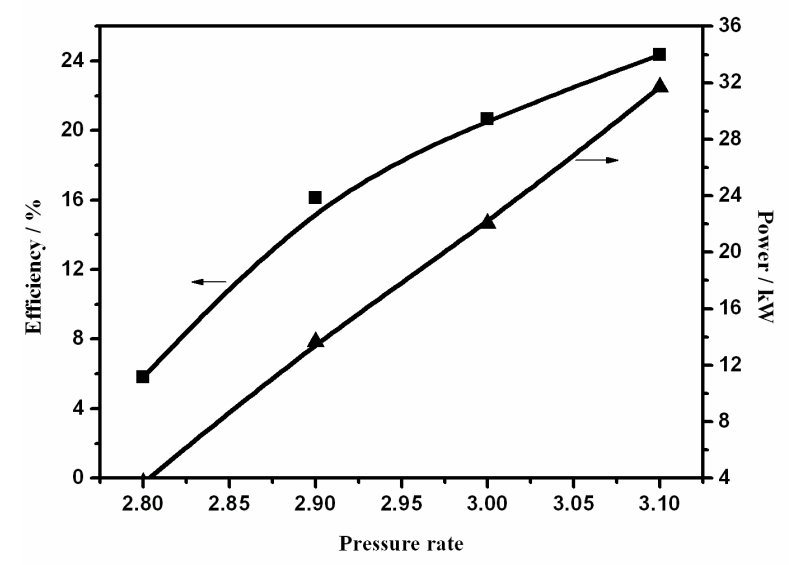

Figure 6. Efficiency and power at $0.95 \mathrm{~N}$

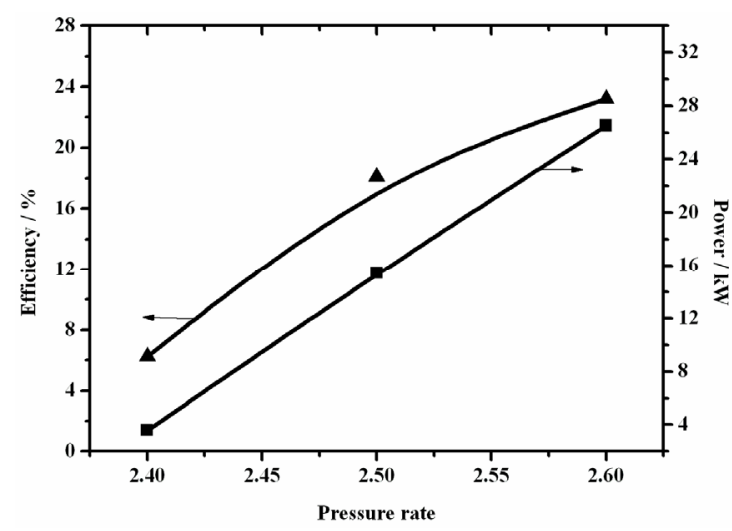

Figure 7. Efficiency and power at $0.9 \mathrm{~N}$

The matching between compressor and turbine can be achieved by the adjustment of the operation parameters of micro-gas turbine. But the adjustment is not good enough as it will cause the lower efficiency, exceeding temperature and even the danger of compressor surge.

\subsubsection{Modification of Compressor and Turbine}

In general the micro-gas turbine does not adopt the technology of variable-area nozzle or stationary blade [20], the vane of compressor is very thin and the modification of variable-area nozzle or stationary blade will be very difficult. But the advantages will be great in the view of the operations if the compressor and turbine can be modified.

Some theoretical calculations have been done on the supposing that the modification of compressor and turbine can be realized. The calculation started from the operation point in case4. Firstly was the modification of compressor. Starting from the operation point in case 4 and then decreasing the flux of air while keeping the compression ratio unchanged. The turbine inlet temperature will increase due to the increase of fuel flux. The inlet temperature of turbine attained the design value and the output of micro-gas turbine was $35.02 \mathrm{~kW}$ when the mass flow of air is 0.965 design value. For the purpose of protecting turbine the turbine inlet temperature should be kept constant after this point. This time the turbine inlet temperature was kept unchanged and the decrease of the compressor flux would result the decrease of 
power from turbine and micro-gas turbine until the output power reached the design value. The relation of efficiency and output power of micro-gas turbine with the decrease of mass flow of compressor was shown in Figure 8.

The operation can also be improved if the flux ability of turbine can be increased with modification. Changing the setting angle or height of stationary blade can increase the flux area of turbine and improve the operations. The calculation point also started from the operation point in case4. The turbine inlet temperature would increase with the increase of turbine flux ability which caused the increase of output power and efficiency until the turbine inlet temperature attained the design value. After this point the increase of flux ability of turbine will cause the decrease of the turbine inlet pressure and the

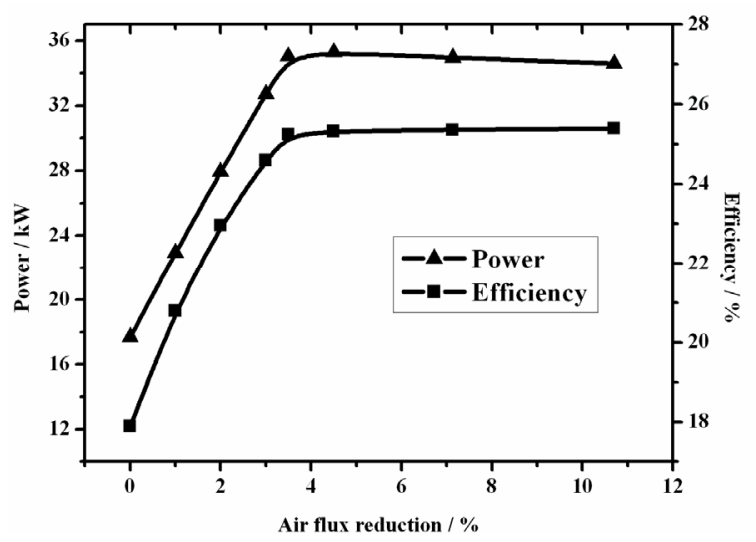

Figure 8. Effect of compressor flux decrease on efficiency and power

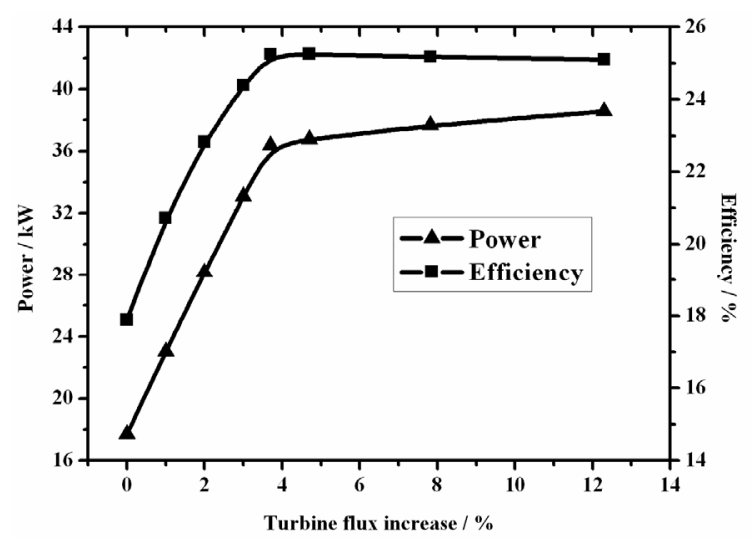

Figure 9. Effect of turbine flux increase on efficiency and power compression ratio of compressor. The power and efficiency still increased slowly because the mass flow of gas keeps increasing at the highest temperature. The relation of power and efficiency with the increase of flux ability of turbine was shown in Figure 9.

The operations of micro-gas turbine were satisfactory with the modification of compressor and turbine. But the modification of compressor or turbine can cause the output of micro-gas turbine beyond the design value which maybe has effect on the structure of micro-gas turbine.

\subsection{Temperature Field of Combustion Chamber}

The matching problem can be solved by the methods mentioned above. But the temperature field in combustor will changed as the changed inlet conditions. The temperature fields in four different conditions were calculated which included the design condition, speed adjustment and the modification of compressor and turbine.

The main parameters for temperature field were maximum temperature, average temperature and nonuniformity coefficient which have effects on the safety of turbine. Figure 10(a) is the temperature distribution characteristic of combustor outlet and axis direction at design condition and it was also the example compared by the other conditions. The maximum temperature, minimum temperature, average temperature and nonuniformity coefficient were shown in Table 3 . The nonuniformity coefficient $A_{t}$ should be lower than $10 \%$ for the safety of turbine.

The temperature field and non-uniformity coefficient were shown in Figure 10(b) and Table 3 when the rotation speed was $0.9 \mathrm{~N}$ and output power was design value. In the axis direction the high-temperature area become larger and at the combustion chamber outlet the maximum temperature and non-uniformity coefficient exceeded the safety margin. So the speed adjustment method was not feasible in the view of turbine safety.

The computation results shown in Figure 10(c) and $10(d)$ were the conditions when modifying the compres- 
Table 3. Combustion chamber temperature characteristics

\begin{tabular}{ccccc}
\hline NO. & $\mathrm{T}_{\max }$ & $\mathrm{T}_{\min }$ & $\mathrm{T}_{\text {ave }}$ & At\% \\
\hline $\mathrm{a}$ & 1179 & 1080 & 1119.2 & 5.4 \\
$\mathrm{~b}$ & 1357 & 915 & 1092.3 & 24.3 \\
$\mathrm{c}$ & 1148 & 976 & 1063.2 & 8 \\
$\mathrm{~d}$ & 1170 & 898 & 1072 & 9.2 \\
\hline
\end{tabular}

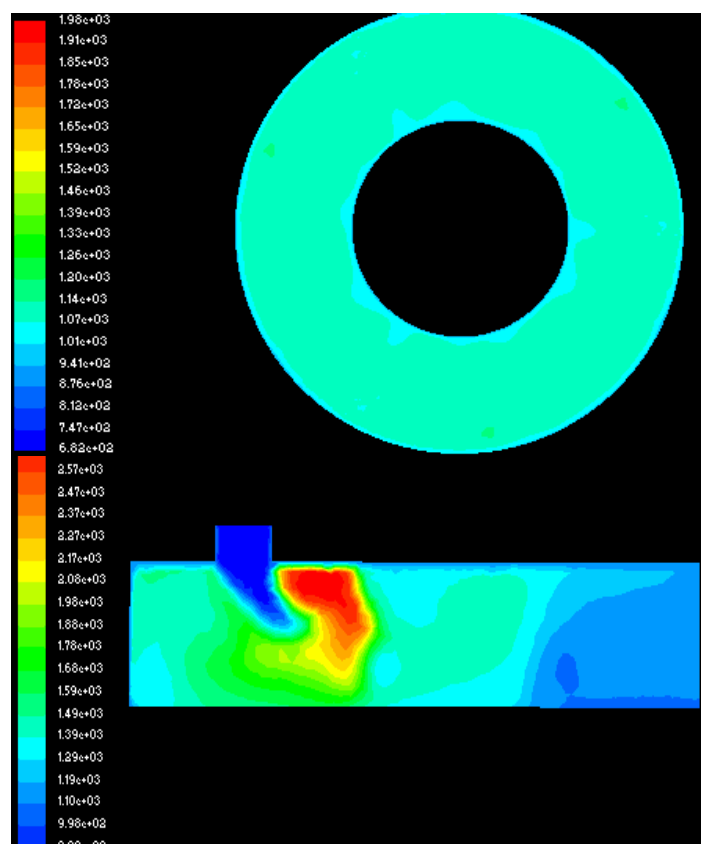

(a)

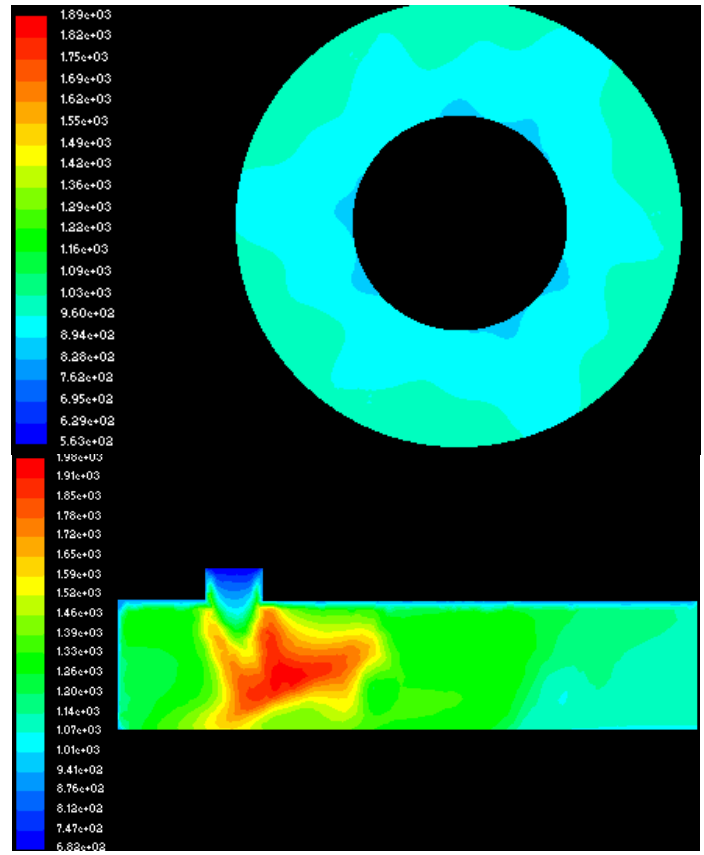

(b)

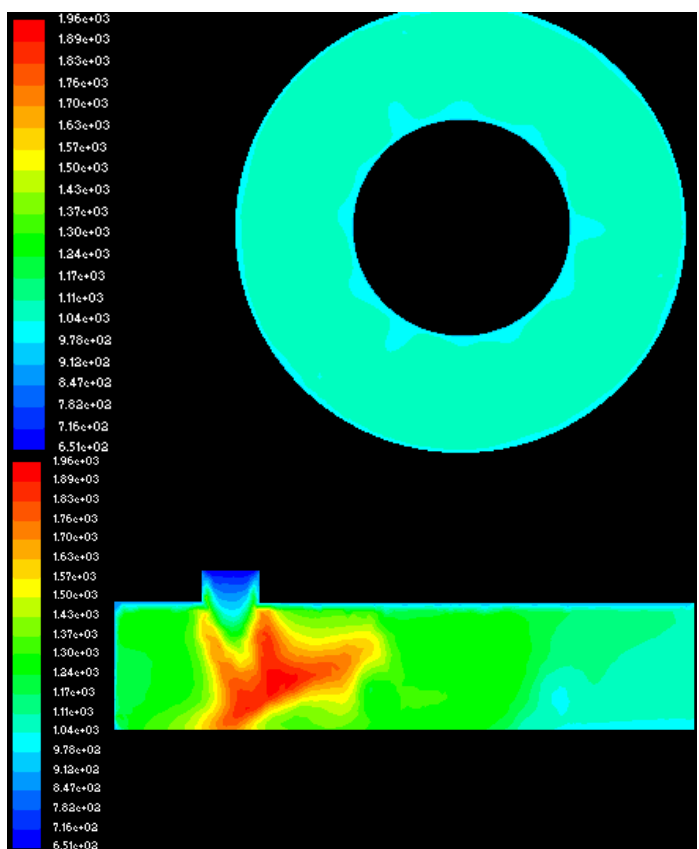

(c)

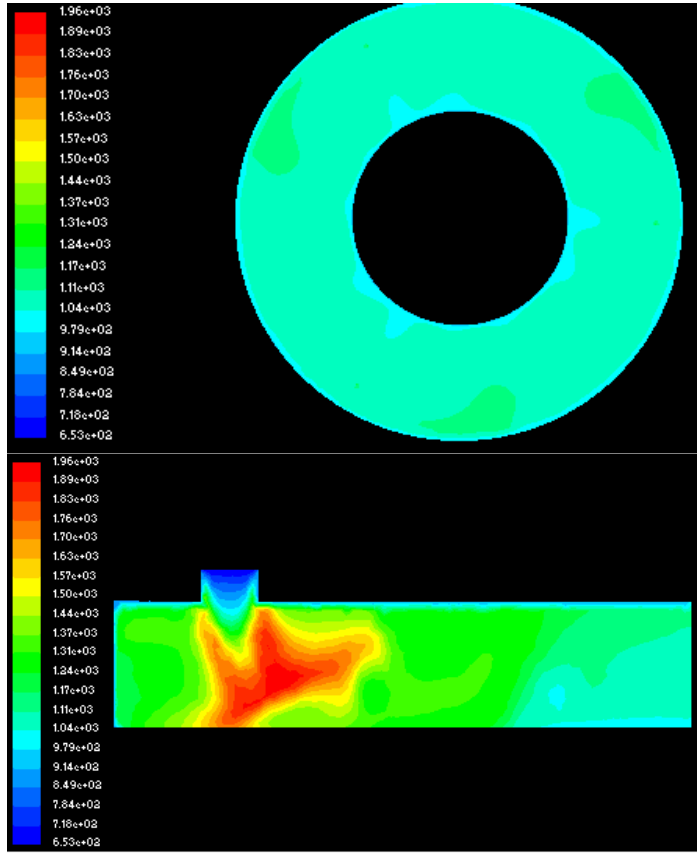

(d)

Figure 10. Outlet and axial temperature field

sor and turbine respectively. In the axis direction the high-temperature area was larger compared with a. The maximum temperature and non-uniformity coefficient at the turbine outlet can meet the safety need. In the view of temperature field the modification of compressor and turbine was feasible. 


\section{Conclusions}

The problems caused by LHVF and some possible adjustment and modification methods have been presented and discussed in this paper. The operations and feasibilities using these methods on micro-gas turbine have been discussed according to the efficiency, output power and temperature field in combustion chamber.

1) Adjustment of operation parameters. The efficiency and output power will decrease when the operation parameters such as compression ratio, turbine inlet temperature are adjusted. So the adjustment of compression ratio and turbine inlet temperature is not feasible in the view of output, efficiency and safety. There are also some problems when adjusting the compressor speed. The matching problem can be solved by the speed adjustment but some additional problems will appear because the micro-gas turbine is coaxial. At the same time the temperature field distribution is uneven at the combustion chamber outlet which can cause the damage of turbine vane. So the adjustment of micro-gas turbine is not feasible to solve the problems caused by LHVF as heavy gas turbine.

2) The modification of compressor and turbine can solve the matching problem and the efficiency is high enough. The maximum temperature and the non-uniformity coefficient of combustion chamber are both in the limitation. So the modification to the compressor and turbine is a good method.

In this paper we only discuss the problem of matching and temperature field, but another problem is ignition and combustion stability. The fuel velocity will be increased which can cause the problem of ignition and combustion stability in combustion chamber. Some further studies about the fuel nozzle and combustion chamber should be made as heavy gas turbine.

\section{Nomenclature}

$$
\begin{array}{ll}
\mathrm{T}_{0} & \text { atmosphere temperature (k) } \\
\mathrm{P}_{0} & \text { atmosphere pressure (Mpa) }
\end{array}
$$

$\mathrm{T}_{\mathrm{ex}} \quad$ gas turbine exhaust temperature (k)

$\mathrm{T}_{3} \quad$ turbine inlet temperature (k)

$\mathrm{G}_{\mathrm{g}} \quad$ turbine gas flux $(\mathrm{kg} / \mathrm{s})$

$\mathrm{P} \quad$ gas turbine output (w)

$\mathrm{N}$ micro-gas turbine design speed $(96000 \mathrm{r} / \mathrm{m})$

Eff efficiency (\%)

$\phi \quad$ the general variable, it can represent the velocity of $u 、 v 、 \mathrm{w}$, turbulent kinetic energy, Turbulence Dissipation Rates, enthalpy, turbulence stress term and Duo-mixture fraction;

$\Gamma_{\phi} \quad$ turbulence transportation coefficient,

s Source term

$\mathrm{T}_{\max }$ combustion chamber outlet max temperature (K)

$\mathrm{T}_{\min }$ combustion chamber outlet min temperature $(\mathrm{K})$

$\mathrm{T}_{\text {ave }}$ combustion chamber outlet average temperature (K)

$\mathrm{A}_{t} \quad$ combustion chamber non-uniformity coefficient

\section{Acknowledgements}

We would like to acknowledge the National Science Foundation of China who provided the funding for this work. This work was partially supported by Shanghai government.

\section{REFERENCES}

[1] Shi Su and Jenny Agnew, "Catalytic combustion of coal mine ventilation air methane,” Fuel, Vol. 85, pp. 1201-1210, 2006.

[2] G. Kelsall and M Cannon, "Combustion of low heating value gas in a gas turbine," Power Production from Biomass, Espoo, Finland, Vol. 2, March 1995.

[3] L. L. Smith, H. Karim, M. J. Castaldi, S. Etemad, and W. C. Pfefferle, "Rich-catalytic lean-burn combustion for fuel-flexible operation with ultra low emissions," Catalysis Today, Vol. 117, No. 4, pp. 438-446, 2006.

[4] Magnus Berg, E. Magnus Johansson, and Sven G. Järås, "Catalytic combustion of low heating value gas mixtures: Comparison between laboratory and pilot scale tests," Catalysis Today, Vol. 59, No. 1-2, pp. 117-130, 2000.

[5] Susie Wood and Andrew T. Harris, "Porous burners for lean-burn applications," Progress in Energy and Combustion Science, Vol. 34, No. 5, pp. 667-684, 2008.

[6] J. J. Witton, E. Noordally, and J. M. Przybylski, “Clean catalytic 
combustion of low heat value fuels from gasification processes," Chemical Engineering Journal, Vol. 91, pp. 115-121, 2003.

[7] Magnus Berg, E. Magnus Johansson, and Sven G. Jaras, "Catalytic combustion of low heating value gas mixtures: Comparison between laboratory and pilot scale tests," Catalysis Today, Vol. 59, pp. 117-130, 2000.

[8] Piero Colonna and Paolo Silva, "Dense gas thermodynamic properties of single and multicomponent fluids for fluid dynamics simulations," Journal of Fluids Engineering, Vol. 125, No.3, pp. 414-427, 2003.

[9] Technology Reference, Capstone Model C30 Performance.

[10] H. S. Zhang, Y. W. Liu, M. Su, and S. L. Weng, "Simulation study on the speed regulation of gas turbine," Computer Simulation, Vol. 1, pp. 79-81, 2002.

[11] Zhang Huisheng, Weng Shilie, and Su Ming, "Dynamic modeling and simulation of distributed parameter heat exchanger," Processing of ME TUBRO EXPO, Nevada, GT2005-68293, 2005.

[12] Huisheng ZHANG, Shilie WENG, and Ming SU, "Evaluation of topping and bottoming cycle hybrid power plants with mcfc-micro turbine," ASME Paper GT2004-53397, 2004.

[13] Iskender G and Etienne Lebas, "Alternative fuels for industrial gas turbines (AFTUR)," Applied Thermal Engineering, Vol. 24, pp. 1655-1663, 2004
[14] Belkacem Adouane, Peter Hoppesteyn, Wiebren de Jong, and Marco van der Wel, "Gas turbine combustor for biomass derived LCV gas, a first approach towards fuel-NOx modelling and experimental validation," Applied Thermal Engineering, Vol. 22, pp. 959-970, 2002.

[15] Greg Kelsall and Christian Troger, "Prediction and control of combustion instabilities in industrial gas turbines," Applied Thermal Engineering, Vol. 24, No. 2, pp. 1571-1582, 2004.

[16] KRISTER STAÊ HL and MAGNUS NEERGAARD, "IGCC power plant for biomass utilisation," Biomass and Bioenergy, Vaè Rnamo, Sweden, Vol. 15, No. 3, pp. 205-211, 1998.

[17] CHARLES E. NEILSON, "LM2500 gas turbine modifications for biomass fuel operation," Biomass and Bioenergy, Vol. 15, No. 3, pp. 269-273, 1998.

[18] Fabio Bozza, Maria Cristina Cameretti, and Raffaele Tuccillo. "Adapting the micro-gas turbine operation to variable thermal and electrical requirements," Transaction of the ASME, Vol. 127, pp. 514-524, 2005.

[19] Xi'an Jiaotong University Department of turbine compressor, "Centrifugal Compressor Principle," Machinery Industry Press, Beijing.

[20] Li Yansheng, "Centripetal turbine and centrifugal compressor," Machinery Industry Press. 